\title{
REAL-WORLD USE OF RITUXIMAB IN RHEUMATOID ARTHRITIS: A RETROSPECTIVE STUDY OF A SINGLE-CENTER IN RIO DE JANEIRO
}

Elisa Benicio Henriques ${ }^{1, \star}$, Manuella Lima Gomes Ochtrop ${ }^{1}$, Leticia Rocha Pereira ${ }^{1}$, Guilherme Brezenski Rodrigues ${ }^{1}$, Camila Souza das Chagas Nogueira ${ }^{1}$, Talita Gonçalves Pereira de Souza ${ }^{1}$, Juliana Murad Faria ${ }^{1}$

1.Universidade do Estado do Rio de Janeiro, Rio de Janeiro (RJ), Brazil.

*Corresponding author: elisa.bhenriques@gmail.com

\section{BACKGROUND}

Rituximab (RTX) is a well-established biological disease modifying antirheumatic drugs (bDMARDs) in patients with rheumatoid arthritis (RA) not responding adequately to synthetic DMARDs. The aim of this study was to describe clinical and laboratory characteristics of RTX in Brazilian patients with RA.

\section{MATERIALS AND METHODS}

Data from 29 patients were collected from medical charts made between January 2011 and September 2020. Included patients were followed at the biologic outpatient clinic of a tertiary university hospital. Patients characteristics were described using mean, standard deviation (SD), median, range, frequency and percentage.

\section{RESULTS}

Patient characteristics are shown on Table 1. Most patients received a $1 \mathrm{~g}$ infusion of RTX on days 0 and 14 , every 6 months. The median cumulative RTX dose was $7.74 \mathrm{~g}$ (SD 5.12, 2-26 g). Median follow-up time after RTX initiation was 46 months (SD 35.13, 6-84 months). Four patients (13,7\%) were refractory to RTX. Mean CDAl evolution is shown on Table 2 and CDAl was classified as high $(>26)$, moderate ( $>11$ and $\leq 26$ ) and low ( $\leq 11)$. Eight (27,5\%) patients had infection events - herpes zoster (1), arbovirus (2), pyodermitis (1), sinusitis, COVID-19 (2), superficial mycosis (1). One patient had a serious infection (hospitalization due to pyelonephritis, requiring venous antibiotic therapy). No patient developed malignancies or tuberculosis.

Table 1. Patients' characteristics.

\begin{tabular}{cc}
\hline Characteristics & $\begin{array}{c}\text { RA patients } \\
(\mathrm{n}=29)\end{array}$ \\
\hline Mean age (SD), years & $53(11.58)$ \\
\hline Erosive disease (\%) & $25(86.2 \%)$ \\
\hline $\begin{array}{c}\text { Rheumatoid Factor and/or } \\
\text { Anti-Citrullinated Protein } \\
\text { Antibody positive, } \mathrm{n}(\%)\end{array}$ & $28(96 \%)$ \\
\hline $\begin{array}{c}\text { Rheumatoid vasculitis (\%) } \\
\text { Average duration } \\
\text { of disease, years }\end{array}$ & $5(17.2 \%)$ \\
\hline $\begin{array}{c}\text { Number of previous } \\
\text { bDMARDs, } \mathrm{n}(\%)\end{array}$ & $\begin{array}{c}15.46 \\
\text { RA patients } \\
(\mathrm{n}=29)\end{array}$ \\
\hline None & $4(13 \%)$ \\
\hline One & $9(31 \%)$ \\
\hline Two or more & $16(55 \%)$ \\
\hline
\end{tabular}

Table 2. Mean CDAl evolution.

\begin{tabular}{ccccc}
\hline $\begin{array}{c}\text { Moment after } \\
\text { RTX first dose }\end{array}$ & $\begin{array}{c}\text { Before } \\
\text { RTX }\end{array}$ & 6 months & 12 months & 24 months \\
\hline $\begin{array}{c}\text { Patients using } \\
\text { RTX (n) }\end{array}$ & 29 & 26 & 23 & 20 \\
\hline $\begin{array}{c}\text { CDAl, } \\
\text { mean (SD) }\end{array}$ & $\begin{array}{c}\text { (15.08 } \\
\text { Patients with }\end{array}$ & $\begin{array}{c}18.33 \\
(10.25)\end{array}$ & $\begin{array}{c}17.93 \\
(15.74)\end{array}$ & $\begin{array}{c}14.85 \\
(13.32)\end{array}$ \\
\hline $\begin{array}{c}18 \\
\text { high CDAI n (\%) }\end{array}$ & $\begin{array}{c}5 \\
(62 \%)\end{array}$ & $\begin{array}{c}5 \\
(19 \%)\end{array}$ & $\begin{array}{c}(21 \%) \\
(15 \%)\end{array}$ \\
\hline $\begin{array}{c}\text { Patients with } \\
\text { moderate CDAl n (\%) }\end{array}$ & $\begin{array}{c}6 \\
(20 \%)\end{array}$ & $\begin{array}{c}15 \\
(57 \%)\end{array}$ & $\begin{array}{c}10 \\
(43 \%)\end{array}$ & $\begin{array}{c}6 \\
(30 \%)\end{array}$ \\
\hline $\begin{array}{c}\text { Patients with } \\
\text { low CDAl n (\%) }\end{array}$ & 5 & 6 & 8 & 11 \\
\hline
\end{tabular}

\section{CONCLUSION}

We observed in our cohort that most patients achieved moderate or low activity after 6 months. Few adverse events have been observed resulting in hospitalization or death even in the presence of high cumulative dose of RTX in some cases. 